\title{
Decomposing the Decline of Cash Assistance in the United States, 1993 to 2016
}

\author{
Zachary Parolin \\ Columbia University
}

\section{Forthcoming at Demography}

\begin{abstract}
Cash assistance allocations from Temporary Assistance for Needy Families (TANF) and its predecessor program fell from $\$ 34.3$ billion to $\$ 7.4$ billion in real value from 1993 to 2016, a 78 percent decrease. Some investigations of TANF point to favorable labor market changes as the source of the decline, while others point to declining benefit levels and barriers to benefit receipt. This study introduces a framework to decompose the decline of TANF cash assistance into changes in need for cash assistance, the participation rate among those meeting income-based eligibility standards, and benefit levels among those receiving cash support. Using the U.S. Current Population Survey, I find that declining participation explains 52 percent of the decline in TANF cash assistance from 1993 onward, whereas declining need explains 21 percent, and declining benefit levels explain 27 percent. The study then applies reweighting techniques to measure the extent to which compositional changes in the population, such as rising employment rates among single mothers, can explain changes in need, participation, and benefit levels. The results suggest that compositional changes explain only 22 percent of the decline of TANF cash assistance, confirming that the majority of the decline is due to reduced participation and benefit levels rather than reduced demand for cash support. Adding the noncompositional share of TANF's decline back to observed levels of cash spending in 2016 would result in nearly $\$ 20$ billion in additional transfers, more than the minimum amount necessary to lift all single-mother households out of poverty.
\end{abstract}




\section{INTRODUCTION}

The provision of cash assistance to low-income families is widely acknowledged as an essential tool for combating child poverty and material hardship. Cross-national research demonstrates that countries that offer the most redistributive support for households with children tend to have lower levels of child poverty (Rainwater and Smeeding, 2003; Brady et al., 2017; Bradbury and Jäntti, 1999). Within the U.S., cross-state research has shown more generous cash assistance schemes contribute to lower levels of hunger, material deprivation, and income poverty among families (Shaefer et al., 2019; Parolin, 2019b; Duncan and Magnuson, 2013; National Academy of Sciences, 2019). After the introduction of the Temporary Assistance for Needy Families (TANF) program in 1996, however, the provision of means-tested cash assistance for jobless, able-bodied families in the U.S. rapidly declined. In 1993, just three years before the passage of the legislation that introduced TANF, annual cash assistance allocations amounted to $\$ 34.3$ billion in 2016 USD. By 2016, annual cash assistance allocations had declined to $\$ 7.8$ billion, a 78 percent decrease from 1993, despite total TANF spending remaining relatively stable over time (Social Security Administration, 2005; Floyd et al., 2017).

The sources of the decline of TANF cash assistance are contested. Some studies point to rising employment rates of single mothers and the declining incidence of single motherhood as explanations for declines in cash assistance (Haskins, 2016; Haskins and Weidinger, 2019). Conversely, some studies point to declining benefit values, harsh participation requirements, and stringent sanction policies as the primary source of decline (Schram et al., 2003; Soss et al., 2011; Edin and Shaefer, 2016; Shaefer et al., 2019). Others have pointed to the fact that inflation has cut the real value of states' TANF block grants by a third, forcing states to use more of their own resources to maintain stable levels of TANF spending (McCabe, 2019). 
This study decomposes the sources of the decline in cash assistance from TANF. In doing so, it adjudicates these competing perspectives of the decline of cash assistance and provides precise estimates on the extent to which changes in the composition of the population, changes in employment rates, or changes in policy choices have contributed to the aggregate decline in cash support from TANF. The results not only provide clarity on the evolution of cash assistance within the TANF program, but also provide broader evidence on the role of welfare reform in shaping trends in poverty in the U.S.

This study proceeds in two analytical steps. First, I introduce an accounting framework to fully decompose changes in cash assistance allocations into changes in four components: the number of households in the population, the share of households meeting the incomebased eligibility standards for TANF cash assistance (need), the share of households meeting the income-based eligibility standards that receive cash assistance (participation), and the mean benefit levels among the households receiving TANF (benefit levels). This accounting framework is applied to answer the study's first question: are changes in need, participation rates, or benefit levels of TANF more consequential in explaining the decline of cash assistance from 1993 to 2016 ?

The second research question builds on the first, asking: to what extent can changes in the demographic and labor market characteristics of the U.S. population explain changes in need, participation, and levels of benefit receipt? I apply reweighting techniques introduced in DiNardo, Fortin, and Lemieux (1996) to estimate how compositional and labor market changes, such as rising employment rates among single mothers, have shaped trends in cash assistance allocations.

The study has three main findings and contributions to the broader social policy literature. First, declining participation rates among households that meet the income-based eligibility requirements for TANF explain the majority (52 percent) of the decline in cash 
assistance from 1993 onward, whereas declining need and benefit generosity explain 21 and 27 percent, respectively. Put differently, only about one-fifth of the decline of cash assistance from TANF can be attributed to improved living standards among low-income families, casting doubt on claims made in more favorable evaluations of TANF (Haskins, 2016). Second, a decomposition analysis suggests that only 22 percent of the decline of TANF allocations can be explained by changes in the composition of the population, confirming that the vast majority of the decline is due to reduced access and benefit levels rather than reduced demand. Finally, adding the non-compositional share of TANF's decline back to observed levels of TANF cash allocations in 2016 would result in $\$ 19.2$ billion in additional cash spending, more than the minimum amount necessary to lift all single-mother households out of poverty.

Notably, the counterfactual addition of $\$ 19.2$ billion in cash assistance, combined with observed spending on cash assistance, is still less than the total sum of funds that states currently spend on all activities within the TANF program (around $\$ 31$ billion in 2016). This fact suggests that the declining real value of states' TANF block grants is not the most important factor in shaping declines in TANF cash assistance. State governments have it within their budgetary capacity today to reduce rates of child poverty through cash assistance from the TANF program.

\section{BACKGROUND}

The Decline of Cash Assistance

TANF was signed into law in 1996 as part of the Personal Responsibility and Work Opportunity Reconciliation Act (PRWORA) and was implemented in all states the following year. Whereas TANF's predecessor, Aid to Families with Dependent Children (AFDC), offered an entitlement to cash assistance for families with incomes below a given threshold, 
TANF enforces work, education, and training requirements to promote employment and the formation of two-parent families (Falk, 2016b).

TANF plays a unique role in the American welfare state. Unlike benefits from the Supplemental Nutrition Assistance Program (SNAP), an important anti-poverty program, cash assistance from TANF can be used on a wide array of household needs rather than simply food items. While access to health insurance through Medicaid is certainly a valuable resource for low-income families, health insurance has a far different effect on most households' consumption capabilities compared to a monthly cash payment. Meanwhile, refundable tax credits, such as the Earned Income Tax Credit (EITC), are conditional on employment and administered annually rather than on a monthly basis. Each of these other safety net programs is important for the wellbeing of low-income families, but they operate differently than cash-based, monthly-distributed social assistance for low-income families.

The legislation that introduced TANF explicitly set out to reduce caseloads and succeeded in that aim. From 1994 to 2016, the number of families receiving AFDC/TANF dropped from 5.1 million to 1.3 million (Falk, 2016b). Specifically, PRWORA transformed three core components of state-administered social assistance. First, it strengthened the conditionality requirements attached to the receipt of cash assistance. Under TANF, cash assistance recipients are required to engage in 'work participation activities' or employment to continue receiving cash support beyond a certain duration (Falk, 2014). Second, the legislation enabled states to allocate TANF funds not only toward the provision of cash assistance, but also toward three other objectives, including the promotion of "job preparation, work, and marriage," the prevention of "out-of-wedlock pregnancies," and "the formation and maintenance of two-parent families." Third, the introduction of TANF replaced an openended, federal matching funding scheme with non-indexed block grants and a mandatory 'Maintenance of Effort' (MOE) requirement (a level of expenditures that states must commit 
to the program) (Falk, 2016a). Put differently, the federal government provides states a fixed sum of funds each year to manage their TANF programs, which states can then add to using their own resources.

The combination of these three changes provided state governments with increasing flexibility in deciding how to utilize their TANF block grants. States can effectively decide who is eligible for TANF benefits, what conditions potential beneficiaries should meet in order to receive benefits, and the level of benefits that a participating individual will receive. More broadly, states can decide to allocate their TANF funds to a wide array of non-cash purposes. In the initial years following the introduction of TANF, state governments spending less on cash assistance were more likely to invest TANF resources in childcare support and other services to facilitate employment. Over time, however, states began to divert TANF funds toward a broad array of programs and services only tangentially related to the core purposes of TANF. By 2016, the average state spent only 24 percent of its TANF budget on cash assistance, down from 56 percent in 1998, despite total TANF spending remaining relatively stable over time (Schott et al., 2018).

\section{Explaining the Decline in Cash Assistance}

What explains the decline in states' allocations of cash assistance from AFDC/TANF? Prior research detailing the decline of cash support can be grouped into three sets of potential explanations: declining demand for cash assistance from TANF, declines in the participation rate among low-income households, and declining benefit generosity of TANF cash assistance. I detail these three explanations in turn.

First, prior research notes that rising employment rates of single mothers (the primary target and beneficiaries of TANF support), rising educational attainment among single mothers, and/or declining single motherhood in general might contribute to TANF's decline (Haskins, 2016; Haskins and Weidinger, 2019; Haider et al., 2003; Grogger and Karoly, 2005; Schoeni 
and Blank, 2000). I refer to these sets of explanations as relating to declining need for TANF cash assistance. Given the labor market gains for single mothers, the decline of cash assistance from TANF may simply represent a declining share of families in need of support. Haskins (2016: 224) writes, for example, that "an increase in work by low-income mothers" and the associated "decline in the welfare rolls" are among the "major and positive effects" of TANF's introduction. ${ }^{1}$ Similarly, state legislators from Georgia have recently credited "the improving economy" for the state's precipitous decline in TANF caseloads (Prabhu, 2019).

Second, prior research shows that even among households that appear to meet the income-based eligibility requirements for TANF, participation rates are steadily declining. Parolin and Brady (2019), for example, find that around 25 percent of income-eligible families received cash support from TANF in 2015 , compared to more than 60 percent of incomeeligible families in 1997. Declining participation among low-income families can likely be attributed to a number of factors, including policy-imposed barriers to TANF receipt (lifetime time limits, work participation requirements, strict sanctioning schemes, penalties for having a child while receiving TANF, and so on), as well as less formal barriers, such as lack of access to state public assistance offices or lack of promotion of low-income households' eligibility for TANF benefits (Soss et al., 2001; Danielson and Klerman, 2008; Ziliak, 2015; Soss et al., 2011; Floyd et al., 2018). ${ }^{2}$ Ethnographic research, for example, finds evidence that some households that are presumably eligible for TANF simply do not know the program still exists (Edin and Shaefer, 2016). These more informal barriers to access can include the stigma associated with benefit receipt (Stuber and Kronebusch, 2004), administrative burdens that make the application process overly onerous for low-income families (Herd and Moynihan, 2018; Currie,

\footnotetext{
${ }^{1}$ Haskins (2016) also acknowledges that the decline of cash assistance might have contributed to a deepening of poverty among disconnected families and those who lack access to stable employment.

${ }^{2}$ A limitation of this analysis is that it is not possible within the data to identify families who have received TANF benefits for the maximum allowed duration and, thus, who are no longer eligible for cash assistance. These families are identified as having incomes below the eligibility standards even if they are not technically eligible for more cash assistance.
} 
2004), and/or individual cost-benefit analyses of whether the benefits are worth pursuing or maintaining. For example, a low-income family that meets the income-based eligibility standards for TANF may simply decide not to pursue the assistance if the benefits are low, if the application process is time consuming, or if the potential for securing employment seems high.

Finally, prior work has signaled that declining benefit levels can help to explain the decline in TANF (Stanley et al., 2016; Hoynes and MaCurdy, 1994). In most states, TANF benefit values are not updated for inflation and, consequently, decline in real value each year. In all but three states, the generosity of TANF benefits has declined from the mid-1990s onward. It is possible, then, that declining benefit levels are a primary source of the decline of overall cash assistance allocations.

To be sure, changes in demand for cash assistance, participation in cash assistance, and benefit levels are products of broader social and political forces. Several studies have examined, for example, how political and racial/ethnic factors are associated with spending on cash assistance (Quadagno, 1998; Brown, 2013; Quadagno, 1994; Soss et al., 2008; Schram et al., 2003; Parolin, 2019b). Other studies have acknowledged that state governments may have a financial incentive to spend little on TANF cash assistance, as they can then use a larger share of their TANF budgets on programs that would otherwise be funded with general state revenues (Parolin and Luigjes, 2019; Germanis, 2015).

This study acknowledges this important work, but is more concerned with the fundamental mechanisms underlying the decline of cash support. If cash assistance from TANF is declining, it must be due to some combination of fewer families needing it, fewer needy families receiving it, or decreases in benefit levels among those receiving cash assistance. While studies have looked individually at these components, it remains unclear how each component contributes to the aggregate decline in cash assistance. Moreover, it remains unclear the extent 
to which compositional and labor market changes deserve credit for the declines in TANF need, participation, and average levels of benefit receipt. After discussing the data sources utilized to answer these questions, the remainder of this study proceeds in two analytical steps. First, I present an accounting framework to decompose the decline of cash assistance into changes in income-based need, participation, and benefit levels. Second, I apply decomposition techniques to estimate the extent to which changes in demographic and labor market characteristics can explain TANF's decline.

\section{ANALYTICAL STRATEGY}

\section{Data Source}

As I present formally in the next section, accounting for the decline in cash assistance allocations from AFDC/TANF is straightforward if the product of four indicators of the U.S. population can be consistently measured over time: the number of households in the population, the share of those households meeting the income-based eligibility criteria for TANF (referred to as need), the share of households in "need" participating in TANF cash assistance (participation), and the mean benefit value among households receiving TANF (benefit levels). Each of these four indicators can, indeed, be measured using micro-data from the U.S. Current Population Survey Annual Economic \& Social Supplement (CPS ASEC).

The standard CPS ASEC, however, suffers greatly from the underreporting of meanstested transfers, such as TANF (Meyer et al., 2009). Thus, I apply benefit adjustments from the Urban Institute's TRIM3 program. In short, TRIM3 utilizes information about each individual and household in the CPS ASEC to predict their likelihood of benefit receipt, as well as the value of benefits that a recipient is likely to receive. The simulations align program participation and benefits in the CPS with federal and state administrative data, taking into account individual/household data on race, ethnicity, immigrant status, marital status, household structure, state of residence, income, state-level policy rules, and more to estimate program 
participation and benefit levels. TRIM3 has been utilized in several recent studies on poverty (e.g. Falk (2015); Winship (2016); Congressional Research Service (2017); Parolin (2019b)) and is also used extensively in the recent National Academy of Sciences report on reducing child poverty (National Academy of Sciences, 2019). The TRIM3-adjusted CPS ASEC sample used in this study includes all heads of households from 1993 to 2016, the three years before TANF was implemented and all available years of TRIM3-adjusted data afterward. ${ }^{3}$

Given recent evidence that TRIM3 may over-allocate SNAP benefits to lower-income households (Stevens et al., 2018), I also replicate findings using the unadjusted CPS ASEC (without TRIM3) in Appendix V. The results are substantively similar. Moreover, I present evidence in Appendix II that TRIM3 more appropriately tracks allocations of cash assistance from TANF relative to the unadjusted CPS ASEC.

While administrative data on TANF benefit allocations would be ideal, only a small number of states provide administrative records that can be merged into the CPS ASEC microdata, and generally only for a small number of years. TRIM3 simulations are the next best alternative. Prior research shows that TRIM3 more closely matches administrative aggregates on benefit allocations than the unadjusted CPS ASEC (Parolin, 2019a). In Appendices I and II, I compare aggregate TANF cash assistance allocations from administrative records, the TRIM3-adjusted CPS ASEC, and the unadjusted CPS ASEC. As the figures show, TRIM3 tracks administrative records with respect to levels and trends in TANF benefit allocations, whereas the unadjusted CPS ASEC does not.

Measuring Income-Based Need: An added benefit of TRIM3 is that its simulation procedures estimate whether each unit meets the income eligibility threshold for TANF benefits and its likelihood of participating in TANF. I measure income-based need as whether the

\footnotetext{
${ }^{3}$ I designate the lead earner in each household as the head. If two adults in the household earn the same amount, I select the oldest of the equal earners as the head. If the earners are the same age, I randomize selection of the head among the same-aged equal earners. When measuring trends in household receipt of TANF, precise selection of the head is not consequential, as benefit levels are measured at the household level.
} 
household meets its state's eligibility criteria for TANF cash assistance based on its income and countable assets.

In estimating whether a family unit meets the income-based eligibility criteria for TANF, TRIM3 "follows the same steps as would be followed by a caseworker, such as applying rules for noncitizens' and students' eligibility, applying the liquid assets (resource) test, computing gross income, calculating deductions to determine net income, and performing the income tests" (Wheaton and Tran, 2018: 30). Income-based eligibility is determined on a monthly basis and takes into account state-level variation in eligibility rules, broad-based categorical eligibility policies, and state waivers for participation among able-bodied workingage adults. Importantly, this estimation of "need" is based on observed characteristics from the survey data and cannot explicitly measure behavioral violations of TANF's eligibility criteria, such as a failure to meet work participation requirements or eclipsing TANF's lifetime time limits. Note, however, that around 44 percent of TANF households are not subject to time limits, time-limit closures only account for around 2-3 percent of TANF exits, and most of the decline in AFDC/TANF caseloads is due to fewer entrants rather than time-limited exits (Farrell et al., 2008; Grogger et al., 2003). Thus, this measure of "need" should be interpreted as meeting the income and asset guidelines for benefit eligibility, but it overstates the share of households that are truly eligible for TANF cash assistance. ${ }^{4}$

Measuring Participation: TRIM3 then simulates participation among households meeting the income-based eligibility criteria. Recall that "participation" is the third of the four components in the decomposition framework. TRIM3's simulations consider program participation and benefit allocation data from federal and state administrative records when assessing the likelihood that a given household within the CPS ASEC received TANF

\footnotetext{
${ }^{4}$ TRIM3 uses income from rents, royalties, interest, dividends, estates, and trusts as a measure of asset income. Many states link their TANF eligibility criteria to the federal poverty guidelines, which are updated for inflation. As such, eligibility cutoffs do not, on average, decline in real value at the same rate as maximum TANF benefit levels.
} 
benefits. If a household meets the income-based eligibility criteria for TANF benefits and reports receiving TANF benefits, TRIM3 keeps the household as participating. Again, the TRIM3 simulations much more closely match administrative records on benefit receipt.

Measuring Benefit Levels: Once a participation decision is established, computing the benefits that a participating household receives - the final component of the decomposition framework - is a straightforward calculation based on state policy rules and features of the household. In sum, TRIM3's simulations of TANF cash assistance allow for a decomposition of the decline of TANF into the four components identified in the prior section: need, participation, benefit levels, and the number of households in the population.

\section{Measuring the Contributions of Need, Participation, and Benefit Levels}

Using the data from the CPS ASEC and TRIM3, the decline of TANF cash assistance allocations can be decomposed into four parts utilizing the following framework:

$$
A_{t}=H_{t} * \frac{N}{H_{t}} * \frac{P}{N_{t}} *{\overline{B_{P}}}_{t}
$$

The total allocation $(A)$ of TANF cash assistance at a given time $(t)$ is the product of the number of households $(H)$, the share of all households meeting the income-based needs cutoff to receive cash assistance from TANF $\left(\frac{N}{H}\right)$, the share of all households in need actually receiving TANF cash assistance in the given year $\left(\frac{P}{N}\right)$, and the mean benefit value among TANF recipients $\left(B_{P}\right)$. This equation simplifies to two core components: the number of TANF participants, $P$, and the mean benefit value among the participants, $\overline{B_{P}}$. But conceptualizing changes in TANF cash assistance allocations as changes in each of these four components allows us to disentangle the broader mechanisms contributing to the decline of cash assistance. 
By way of example, consider the following scenario. In Year $T$, a population of 100 households received a combined $\$ 750$ in TANF cash assistance allocations. In Year $T+1$, the population grew to 105 households, but received a combined \$630 in (inflation-adjusted) cash allocations. What explains this $\$ 120$ decline? Simply knowing the number of households participating in TANF $(P)$ and the mean cash assistance value among those households $\left(\overline{B_{P}}\right)$ provides a useful start toward answering that question. But identifying each of the elements in Equation (1) provides more detailed insight into whether the changes can be attributed to changes in need, participation among households in need, or mean benefit values among households participating. Following Equation (1), let's say the calculations for the two years are as follows:

$$
\begin{gathered}
\$ 750_{\mathrm{t}}=100_{\mathrm{t}} * 0.3_{\mathrm{t}} * 0.5_{\mathrm{t}} * \$ 50_{\mathrm{t}} \\
\$ 630_{\mathrm{t}+1}=105_{\mathrm{t}+1} * 0.4_{\mathrm{t}+1} * 0.3_{\mathrm{t}+1} * \$ 50_{\mathrm{t}+1}
\end{gathered}
$$

Thus, in $\operatorname{Year} T, 30$ percent of households in the population meet the income-based eligibility criteria for TANF. Among those 30 households meeting the needs standard, 50 percent actually receive TANF cash assistance. And among the 50 households receiving TANF, the mean benefit value is $\$ 50$. What explains the decline in allocations from that year to the next? We can see quite clearly that it is not due a decline in the share of households meeting the needs standard, as "need" increased to 40 percent. Instead, the decline in participation - the share of income-eligible households receiving the benefit - from 50 percent to 30 percent appears to explain the decline. In fact, we can estimate that if the participation rate of TANF benefits remained unchanged at 50 percent between the two years, cash allocations in Year $T+1$ would have amounted to $\$ 1,050$, a large increase rather than a decline.

Building on the framework offered in Equation (1), I first compute the relative contribution of each of the four components to the year-to-year and cumulative change in 
TANF cash assistance allocations. We know, for example, that cash assistance allocations $(A)$ decreased by about $\$ 2$ billion from 1999 to 2000 . To what extent was this $\$ 2$ billion decline due to changes in, say, the participation rate $\left(\frac{P}{N}\right)$ of TANF benefits? We can measure this as follows, for now using the example of changes in participation:

$$
A_{\left(t \mid \bar{N}_{t-1}\right)}=H_{t} * \bar{H}_{t} * \frac{P}{N_{t-1}} *{\overline{B_{P}}}_{t}
$$

The only difference between Equation (1) and (2) is that Equation (2) includes the prior year's share of participation rate $\left(\frac{P}{N_{t-1}}\right)$, rather than the observed year's share, into the calculation. This produces a counterfactual allocation of TANF cash assistance, $\left.A_{\left(t \mid \frac{P}{N}\right.}\right)_{t-1}$, in which the participation rate of TANF benefits had not changed from the prior year. Using the products of Equations (1) and (2), we can then straightforwardly compute the contribution of the change in participation to the overall change in TANF cash allocations between the two years. This is calculated simply as $\left.A_{t}-A_{\left(t \mid \frac{P}{N_{t-1}}\right.}\right)$.

I then repeat this process for participation, need, and benefit levels for each year from 1993 onward to provide a descriptive portrait of how changes in each component have contributed to year-to-year changes in TANF allocations, as well as aggregate changes in TANF cash assistance allocations from 1993 to 2016. In other words, the decomposition is run for each possible 'order' of changes in need, participation, and benefit levels for each year. As the four components operate independently (a change in participation does not lead to a mechanical change in average benefit values, for example), the sums of their four respective counterfactuals in each year add up to the aggregate year-to-year change in cash assistance allocations. As such, applying Equation (2) informs us of which of the components has contributed most to changes in TANF cash assistance allocations over time, as asked within the study's first research question. 
Can Compositional Changes Explain Changes in TANF Need, Participation, and Benefit Levels?

With the first question answered, we can then move toward answering the second: to what extent can changes in demographic characteristics and labor market conditions explain changes in TANF need, participation, and benefit levels? To answer this, I first apply reweighting techniques to produce a 'composition-consistent' population of U.S. households from 1993 to 2016. I then decompose changes in need, participation, and benefit levels for each year into two components: a share that can be "explained" by changes in demographics and household characteristics, and a share that is not explained by such changes. I refer to the unexplained portion as the non-compositional share of TANF's decline. We can assume (and later, empirically test) that much of the non-compositional share of TANF's decline can be attributed to state-level policy changes (in the case of need), formal and informal barriers to TANF participation among the eligible (in the case of participation), and a decline in real benefit values (in the case of benefit levels).

To compute the composition-constant estimates, I apply a reweighting approach introduced in DiNardo et al. (1996) (DFL). In short, the DFL decomposition reweights the population in a given year to match the characteristics of a population in a separate year. In the context of this paper, I reweight the population in each year from 1994 to 2016 to match the composition of the 1993 population, the first year of analysis in this study. Specifically, I reweight the sample so that all demographic and household characteristics are constant across all years. This includes age of the household head, education of the household head, sex, family structure (dummies for single mother, single father, female head with children, male head with children, with households without children as reference), employment status (dummies for household joblessness, dual earnership, full-time status of head, and number of weeks unemployed in prior year), race/ethnicity of household head, number of children in the household, as well as interactions among the family structure, education, age, and 
employment characteristics. I then use the revised weights to estimate counterfactual means of need, participation, and benefit levels in each year if the composition and labor market characteristics of the population had not changed from 1993 onward.

Formally, the reweighting function is modeled as:

$$
\psi(\mathrm{x})=\frac{\operatorname{Pr}\left(t_{x}=1993 \mid x\right)}{\operatorname{Pr}\left(t_{x}=t \mid x\right)} \cdot \frac{\operatorname{Pr}\left(t_{x}=t\right)}{\operatorname{Pr}\left(t_{x}=1993\right)}
$$

$\operatorname{Pr}\left(t_{x}=t \mid x\right)$ is the probability of being in year $t$ conditional on individual/household attributes $x$, as listed above. This is estimated using a probit model. The year 1993 is set as the common baseline year, and the weights for each subsequent year from 1994 to 2016 are adjusted to match the composition of the 1993 population. ${ }^{5}$ I multiply the given weights in the CPS ASEC by the new weighting function, $\psi(\mathrm{x})$, and use the new weights to produce a counterfactual change in need, participation, and benefit levels. Using these counterfactual estimates, I can calculate the extent to which differences in the observed levels in the three components can be explained by demographic/household features and, conversely, the extent to which the changes are not explained by compositional changes. Formally, the noncompositional share of TANF's decline can be defined as follows, using the example of the share of changes in need unexplained by compositional differences $\left(U_{\bar{N}_{t}}\right)$ :

$$
U_{\bar{H}_{t}}=\frac{N}{H}_{(t \mid x=1993)}-\bar{H}_{(t \mid x)}
$$

If differences in composition - such as single parenthood, household size, employment, and so on - were the only factors explaining differences in need, then the difference between the counterfactual $\left(\frac{N}{H}(t \mid x=1993)\right)$ and observed values for $2016\left(\frac{N}{H}(t \mid x)\right)$ would

\footnotetext{
${ }^{5}$ When estimating the unexplained share of changes in TANF eligibility, I reweight the entire population to match the 1993 composition. For the unexplained share of changes in participation among the eligible (participation), I reweight the given year's sample to match the composition of households that were eligible in 1993. And for the unexplained share in benefit levels, I reweight the given year's sample to match the composition of the participating households in 1993.
} 
be zero. In this scenario, the change in need unexplained by compositional differences, $U_{\frac{N}{H_{t}}}$, would be likewise be zero. Using this same logic, we can calculate the unexplained (noncompositional) share of changes in need, participation, and benefit levels for each year.

As a final step, we can compute a counterfactual allocation of TANF cash assistance in a given year if the unexplained decline in each of the components were to be added back into the observed values of cash assistance. Creating a counterfactual allotment of cash assistance provides us an estimate of how much would be spent on TANF cash assistance in a given year if trends in allocations fluctuated only due to the composition and characteristics of the U.S. population, rather than, say, efforts to limit access to TANF benefits. The counterfactual can be defined formally as:

$$
A_{(t \mid x=1993)}=H_{t} *\left(\frac{N}{H_{t}}+U_{\bar{H}_{t}}\right) *\left(\frac{P}{N_{t}}+U_{\bar{N}_{t}}\right) *\left({\overline{B_{P}}}_{t}+U_{\overline{B_{P} t}}\right)
$$

Again, $U$ represents the share of the component's decline unexplained by changes in the composition of the population. The product, $A_{(t \mid x=1993)}$, thus provides the counterfactual cash assistance allocations in 2016 if the unexplained decline (that not attributable to changes in composition) in need, participation, and benefit levels were added back into the observed allotment of cash support.

\section{FINDINGS}

\section{Descriptive Findings}

Figure 1 presents descriptive findings on trends in income-based need, participation, and benefit levels of TANF from 1993 to 2016. The share of households meeting the incomebased eligibility requirements for TANF ("need") has declined from an estimated 7.4 percent of all households in 1993 to 5 percent of all households in 2016. Most of this decline in need occurred after the introduction of TANF: from 1998 to 2016, the share of households meeting the needs standard fell from 6.7 percent to 5 percent. 
Figure 1: Trends in income-based need, participation, benefit levels in AFDC/TANF
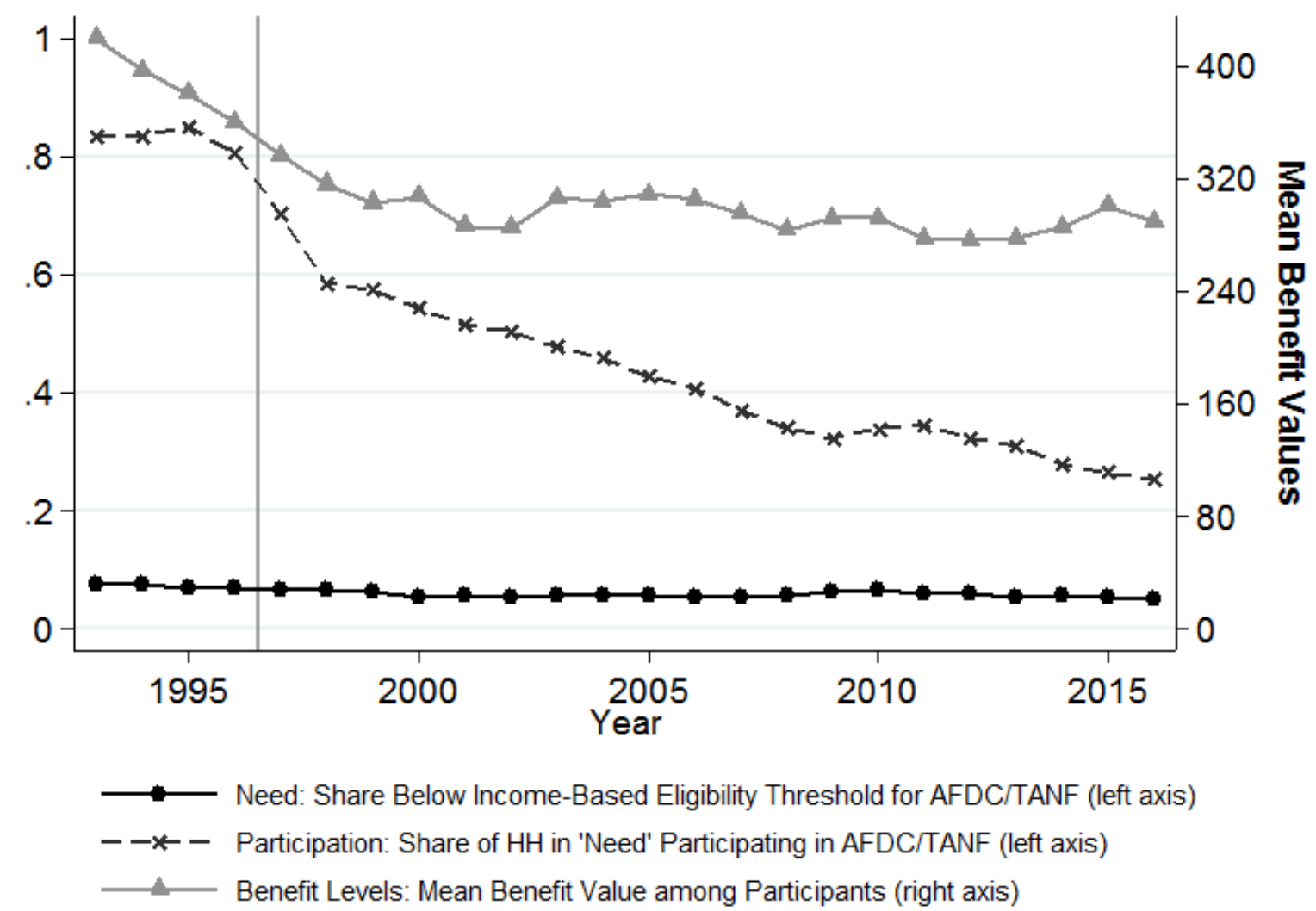

Note: Vertical line represents transition from AFDC to TANF. Need refers to share of households meeting the income-based eligibility criteria to receive AFDC/TANF cash assistance.

In contrast, the participation rate of TANF (share of income-eligible households participating in the program) shows a steep decline over time. In 1993, an estimated 83.3 percent of households meeting the income-based eligibility requirements for AFDC participated in the program. By 2016, participation among the income-eligible dropped to 25 percent. As Figure 1 shows, the transition from AFDC to TANF appears to have contributed to a sharp drop in participation, followed by a steady decline. Benefit levels (right axis) have also shown a notable decline over time. In 1993, the average household participating in TANF received a mean monthly benefit value of $\$ 419$ (in 2014 USD). By 2016, that had fallen to $\$ 289$ per month, a 31 percent decline. The number of households in the population (not depicted) increased from around 97.3 million in 1993 to 126.5 million in 2016. 
Figure 2: Decomposition of year-to-year changes in AFDC/TANF cash assistance allocations

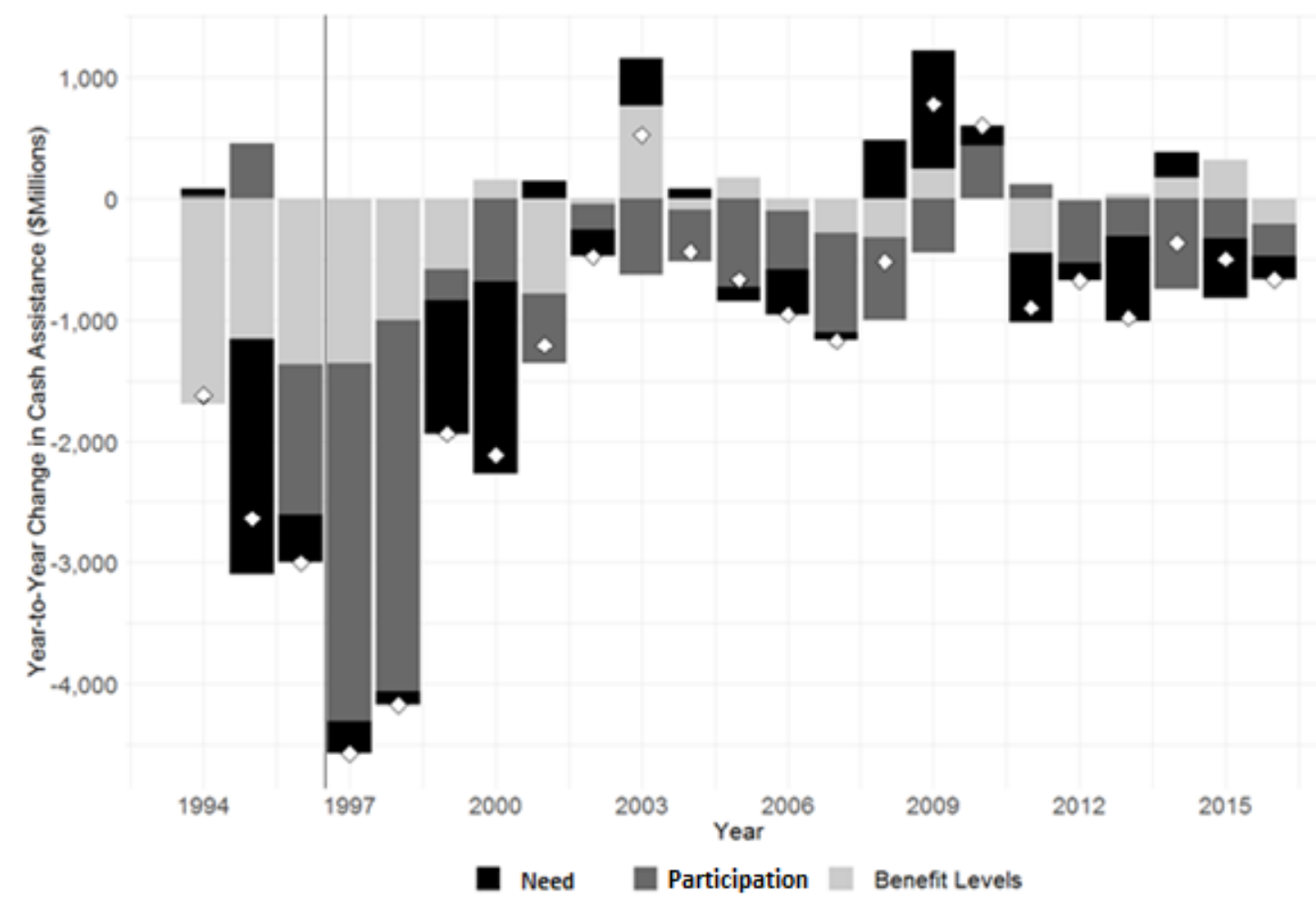

Note: Diamonds represent total change in AFDC/TANF allocations from prior year. Vertical line represents transition from AFDC to TANF. See Equation (2) for details on computation. Need refers to changes in cash assistance due to changes in share of households meeting income-based eligibility criteria.

Following Equation (2) in the prior section, we can now observe how changes in each of need, participation, and benefit levels contributed to year-to-year changes in AFDC/TANF cash assistance spending from 1993 to 2016. Figure 2 shows the results. The diamonds in Figure 2 depict, for each year, the total change from the prior year in AFDC/TANF cash assistance allocations. The stacked black, dark gray, and light gray bars then depict the total change attributable to changes in need, participation, and benefit levels, respectively. From 1993 to 1994, for example, total TANF allocations fell by about $\$ 1.5$ billion. Nearly all of the $\$ 1.5$ billion decline between the two years can be attributed to declining benefit levels. As the descriptive trends presented in Figure 1 revealed, benefit levels declined from around $\$ 419$ to $\$ 397$ in real value between these years, while need and participation remained mostly constant. 
In subsequent years, however, changes in benefit levels were less consequential to the decline in cash assistance from AFDC/TANF relative to declines in need and participation. In the years immediately following welfare reform (1997 to 1999), for example, declines in participation contributed most substantially to the large declines in cash allocations. From 1996 to 1997 , and again from 1997 to 1998 , total TANF cash allocations fell by $\$ 4$ billion per year, with declines in participation driving the majority of the decline. This evidence contradicts claims that rising employment rates among single mothers deserve credit for the initial decline in TANF cash assistance after welfare reform (Haskins and Weidinger, 2019). Instead, policy changes that limited access to TANF cash assistance for families who met the income-based eligibility criteria were the primary drivers of decline from 1996 to 1998.

In contrast, declines in TANF allocations from 1998 to 1999, and then 1999 to 2000, were driven primarily by declines in need, or the share of households that met the incomebased eligibility criteria. From 2001 onward, the composition of cash assistance fluctuations is mixed, but with changes in participation generally contributing most to annual declines. The only two periods in which TANF cash assistance allocations increased were during the early 2000s recession and during the financial crisis of 2008 to 2011. 
Figure 3: Decomposition of cumulative changes in AFDC/TANF cash assistance allocations by changes in need, participation, and benefit levels

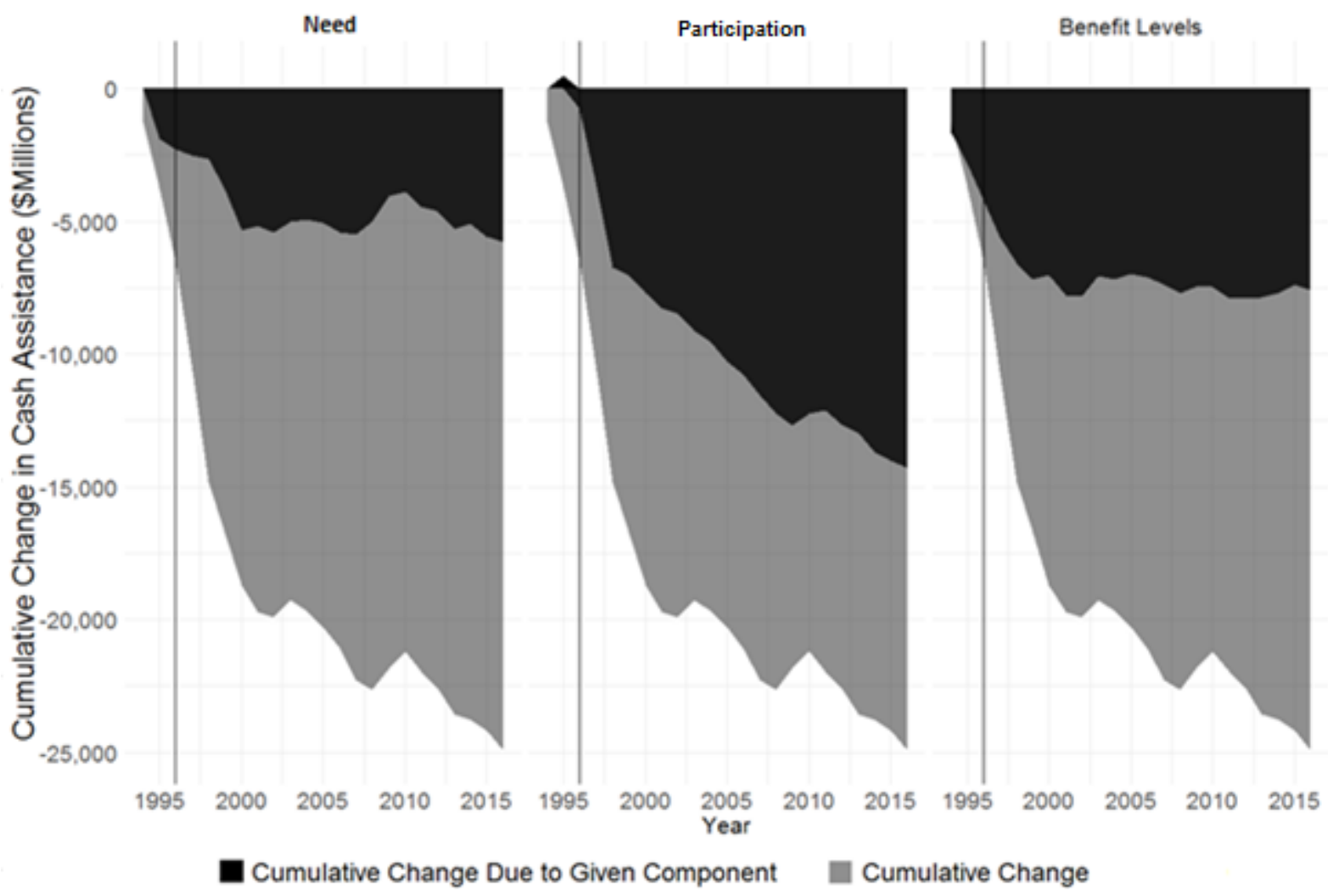

Note: Vertical line represents transition from AFDC to TANF. Need refers to changes in share of households meeting income-based eligibility criteria.

While Figure 2 decomposed year-to-year changes in TANF cash allocations by need, participation, and benefit levels, we can also look at the cumulative contribution of each component to the overall decline in cash assistance. Figure 3 presents these findings. Here, the decline in participation rates (middle panel) and its effect on overall declines in cash assistance becomes more apparent. By 2016, declines in participation explain nearly $\$ 15$ billion of the overall $\$ 25$ billion decline in TANF cash allocations. When adjusted for the increase in the number of households in the population (which contributed to a 10.4 percent increase in TANF cash assistance allocations), declines in participation explain an estimated 52 percent of the total decline in TANF cash assistance allocations. Though declining need was particularly consequential during the initial years after TANF's implementation, its overall effects on TANF's decline were relatively stable from 2000 onward, with the 
exception of the years of the financial crisis. By 2016, declines in need contributed to around $\$ 5.8$ billion (21 percent) of TANF's cumulative decline. Similarly, the contribution of benefit levels led to steep declines in cash assistance allocations from 1993 to 1997, but were then relatively stable from 1998 to 2016. Declines in benefit levels contributed to around $\$ 7.6$ billion ( 27 percent) of the cumulative decline in TANF cash assistance by 2016 .

The consequences of the financial crisis are again visible in Figure 3. Around 2010, need, participation, and benefit levels each see a slight increase, an aberration from their otherwise steady declines. Strikingly, though, those declines continued quickly as the recession faded. All the increases in TANF cash assistance allocations during the recession had, by 2012, been offset by the renewed decline in eligibility and participation.

To what extent can changes in the demographic and labor market characteristics of the population explain these changes in need, participation, and generosity? Put differently, how much of the change in these three components remains unexplained by compositional changes? Applying the DFL reweighting techniques described in the prior section, Table 1 shows the extent to which changes in need, participation, and benefit generosity can be explained by compositional changes in the population from 1993 to 2016. 
Table 1: Share of change in AFDC/TANF income-based need, participation, and benefit generosity explained and unexplained by compositional differences from 1993 to 2016

\begin{tabular}{|c|c|c|c|}
\hline & Need & Participation & Benefit Generosity \\
\hline Value in 1993 & $7.4 \%$ & $83.3 \%$ & $\$ 5,040$ \\
\hline Value in 2016 & $5.0 \%$ & $25.2 \%$ & $\$ 3,468$ \\
\hline Difference & 2.4 p.p. & 58.1 p.p. & $\$ 1,572$ \\
\hline Value in $2016 \mathrm{w} / 1993$ Composition & $7.8 \%$ & $27.6 \%$ & $\$ 3,281$ \\
\hline Unexplained Difference (2016) & -0.4 p.p. & 55.7 p.p. & $\$ 1,759$ \\
\hline Explained Difference (2016) & 2.8 p.p. & 2.4 p.p. & $-\$ 187$ \\
\hline Employment & 0.5 p.p. & 0.6 p.p. & $-\$ 112$ \\
\hline Family Structure & 0.7 p.p. & 0.6 p.p. & $-\$ 30$ \\
\hline Education & 0.7 p.p. & 0.1 p.p. & $\$ 0$ \\
\hline Age of Household Head & -0.1 p.p. & -0.4 p.p. & $-\$ 3$ \\
\hline Interactions & 0.4 p.p. & -0.1 p.p. & $-\$ 1$ \\
\hline Value in 2016 + Unexplained & $4.6 \%$ & $80.9 \%$ & $\$ 5,227$ \\
\hline
\end{tabular}

Note: Estimations from DFL decomposition presented in Equation (3). Sample of 2016 population reweighted to match characteristics of 1993 population. Weighted household counts: 97,262,728 (1993 sample) and 126,500,000 (2016 sample). Due to endogeneity among demographic indicators, sum of subcomponents in "Explained Difference" do not necessarily add up to total of explained difference.

The first set of rows in Table 1 displays the observed values of the three components in 1993 and 2016, and the difference in the values between the two years. In 1993, for example, 7.4 percent of households were eligible for TANF benefits, compared to 5 percent in 2016, a difference of 2.4 percentage points. The subsequent two rows present the value of each component in 2016 after the population is reweighted to match the composition of the 1993 population, and the share of the difference that is unexplained by compositional changes. Finally, the explained portion of the change in each component is presented, including a breakdown of which demographic features, in particular, contributed to the observed change.

If the 2016 sample looked like the 1993 sample (with respect to education, employment, age, household structure, race/ethnicity, and citizenship), the estimated share of households meeting the income-based eligibility criteria ("need") in 2016 would be 7.8 percent rather than 5 percent. Recall that the eligibility rate in 1993 was 7.4 percent. This suggests, first, that changes in the composition of the population from 1993 to 2016 have 
contributed meaningfully to the decline in need for TANF benefits and, second, that need would actually be higher in 2016 than in 1993 if the populations were compositionally equivalent. The results suggest that changes in family structure (a decline in single motherhood) and a rise in educational attainment contributed most to the decline in TANF need, followed closely by changes in employment. The difference between the compositionadjusted estimate in 2016 (7.8 percent) and the observed value in 1993 (7.4 percent) is 0.4 percentage points, which represents the non-compositional share of the change of TANF eligibility.

The middle column shows that if the households meeting the income-based eligibility criteria for TANF in 2016 matched the composition of such households in 1993, the estimated participation rate of TANF benefits in 2016 would increase slightly to 27.6 percent, not much different from the observed value of 25.2 percent. Thus, an estimated 55.7 percentage points of the 58.1 percentage point decline in TANF participation remains unexplained by compositional differences of households in need of TANF.

Meanwhile, benefit levels would actually fall by around $\$ 187$ in 2016 if the composition of households receiving TANF benefits in 2016 matched the composition of those receiving AFDC in 1993. This is small in comparison to the overall $\$ 1,572$ change in TANF benefit levels from 1993 to 2016. An estimated \$1,759 decline in TANF levels remains unexplained by differences in the characteristics of households receiving TANF benefits.

To summarize, changes to family structure, education, and employment appear to fully explain the 2.4 percentage point decline in the "need" for TANF from 1993 to 2016. However, compositional changes fail to explain the vast majority of the decline in TANF participation and benefit levels. Instead, policy changes limiting access to benefits likely explain the decline in participation, while the decline in mean benefit levels among TANF recipients is likely attributable to deliberate policy decisions to cut TANF benefits, or a lack 
of updating benefit values to inflation. In Appendix III and Appendix IV, I test these claims empirically, finding that federal- and state-policy decisions do, indeed, contribute to the 'unexplained' decline in participation and benefit levels. Here, though, I focus on the consequences of the declines for the evolution of cash assistance allocations.

Following Equations (4) and (5), we can add the unexplained decline in need, participation, and benefit levels to the observed values in 2016 to produce a counterfactual allotment of TANF cash assistance. The final row in Table 1 provides these values. The counterfactual share of households in need would decline from 5 percent to 4.6 percent, as the difference not explained by compositional changes was -0.4 percentage points. In contrast, participation would increase from 25.2 to 81 percent in 2016, while annual benefit generosity would increase from $\$ 3,468$ to $\$ 5,227$. The counterfactual cash assistance allotment is calculated as the product of the weighted number of households in the U.S. sample in 2016 $(126,500,000)$ and the values of the three components. This adds up to around $\$ 24.8$ billion an increase of more than $\$ 19.2$ billion in TANF cash assistance spending in $2016 .{ }^{6}$ Given this, we can conclude the following: by 2016, compositional changes could only explain 22 percent of the total decline in TANF cash assistance ( $\$ 5.6$ billion of the $\$ 24.8$ billion decline) from 1993 to 2016 . Conversely, 78 percent of the decline ( $\$ 19.2$ billion of the $\$ 24.8$ billion decline) remains unexplained by compositional change. As observed before, the vast majority of the decline of cash assistance can instead be attributed to reduced accessibility and benefit levels rather than reduced need.

Figure 4 repeats this exercise from 1994 to 2016 to show the evolution of potential cash assistance spending if the unexplained portion of need, participation, and benefit levels were added into each year's TANF allocations. The black area represents the observed TANF

\footnotetext{
${ }^{6}$ These figures are based on TRIM3's estimates of cash assistance allocations in each year within the CPS ASEC. TRIM3 estimates of benefit allocations are slightly lower than administrative records, as show in Appendix I, but much higher and more accurate than estimates from the unadjusted CPS ASEC.
} 
cash assistance allocations in the given year. The gray area reflects the counterfactual increase if the unexplained decline were to be reversed. The first three panels show the change in TANF allocations if only the unexplained share of the respective component were added back in overall TANF allocations, while the final panel shows the counterfactual allocations when the unexplained share for all three are added.

Figure 4: Counterfactual AFDC/TANF cash allocations with unexplained share of component(s) added to observed values in given year

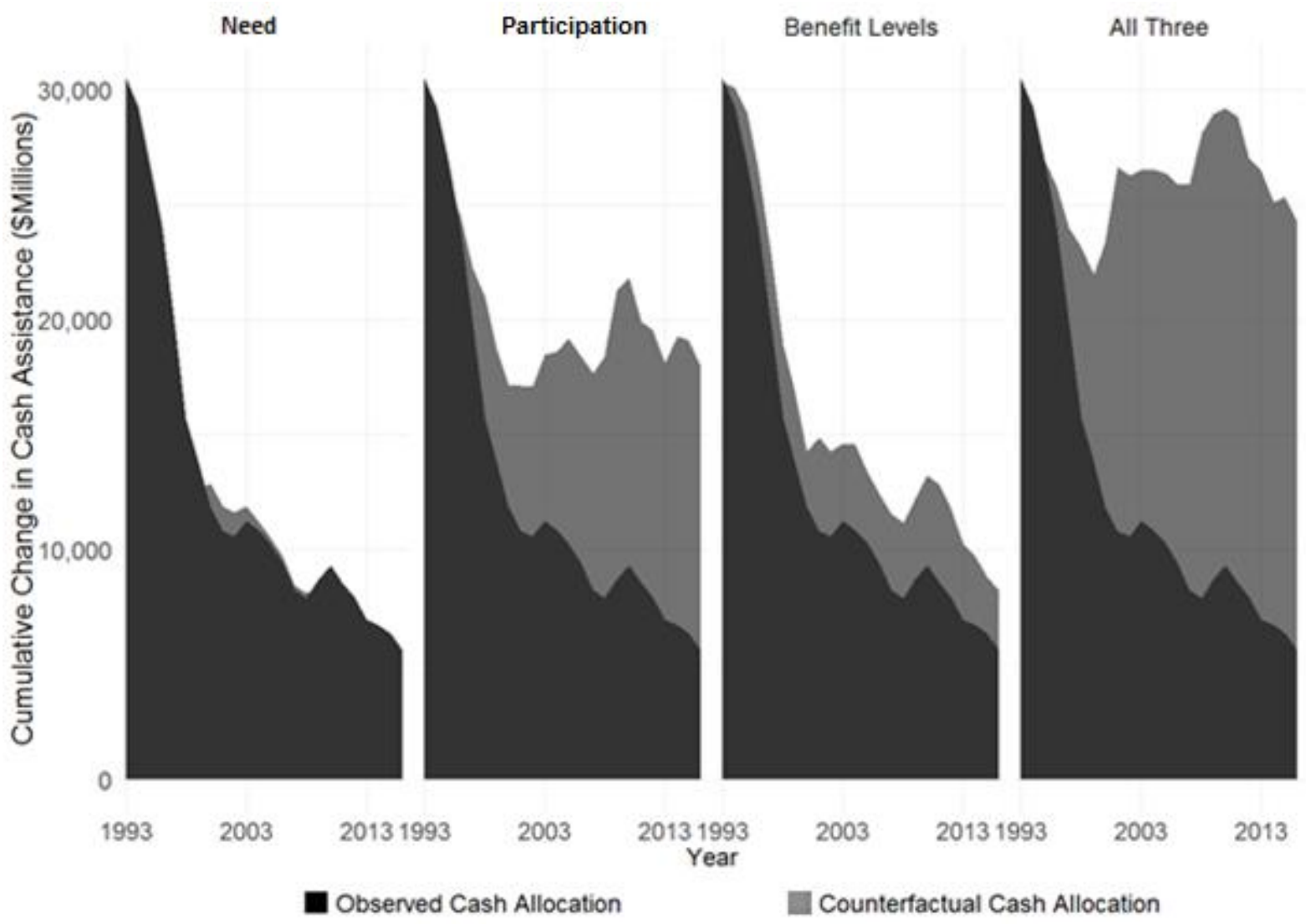

Note: Need refers to meeting the income-based eligibility criteria for TANF.

Figure 4 shows that changes in need in nearly all years are explained by demographic and labor market changes, similar to the results in Table 1 when examining changes in 2016. As such, there is no "unexplained" need to be added back in, and the counterfactual TANF allocations are no greater than the observed allocations. With respect to participation, the second panel, the story is far different. Reversing the unexplained decline in TANF participation would consistently lead to higher TANF cash assistance allocations. The third 
panel shows that the same is true - albeit to a lesser extent - for benefit levels. Finally, the fourth panel shows the effect of reversing the unexplained decline for each of the three components. In this scenario, AFDC/TANF cash assistance spending would never have dropped below $\$ 20$ billion. During the midst of the recent financial crisis, TANF cash assistance would have jumped to nearly $\$ 30$ billion rather than the observed $\$ 9$ billion. And in 2016, as already noted, TANF spending would be $\$ 19.2$ billion higher than the observed level of cash assistance spending. This counterfactual increase in spending would not require new spending appropriations from federal or state governments, as the resources are less than the current combined value of the TANF block grant and required MoE spending.

\section{DISCUSSION}

If demographic change were the only factor driving changes in cash assistance from AFDC/TANF, as opposed to policy changes that have reduced participation and benefit levels from 1993 onward, states would have spent a combined $\$ 19.2$ billion more in cash assistance for low-income families in 2016. To put that amount into perspective, we can compare it to amount of money needed to move all single-mother households - the primary targets and beneficiaries of TANF - out of poverty. In 2016, an estimated 26.2 percent of single-mother households lived in poverty, according to estimates from the Supplemental Poverty Measure (SPM). The aggregate poverty gap - the combined sum of money needed to lift all households to the poverty line - summed to $\$ 14.2$ billion in 2016 . Thus, the additional $\$ 19.2$ billion in TANF cash assistance is more than the minimum amount necessary to lift all single-mother households out of poverty. Even with labor market responses and the realities of imperfect targeting in a redistributive cash assistance scheme, the increase in cash assistance could have a large reduction effect on poverty among single-mother households. ${ }^{7}$

\footnotetext{
${ }^{7}$ To understand why such an increase in TANF spending could achieve the elimination of deep poverty among single-mother households in 2016, yet comparable levels of spending did not achieve large reductions in deep poverty in the mid-1990s, consider that non-TANF social transfers have risen considerably from the mid-1990s onward. In particular, expansions to the Earned Income Tax Credit (EITC) and Supplemental Nutrition
} 
Notably, such a policy shift would require no new redistributive program or allotment of federal funds. The counterfactual addition of $\$ 19.2$ billion in cash assistance, combined with observed spending on cash assistance, is still less than the total sum of funds that states currently spend on all activities within the TANF program (around $\$ 31$ billion in 2016). This again suggests that the declining real value of states' TANF block grants is not the most important factor in shaping declines in TANF cash assistance. However, a reallocation of TANF funds back to cash assistance would require states to pull TANF resources from other programs and services, and some of these alternative services are likely to have value for lowincome families.

Table 2: Change in states' TANF budget allocations after decline in share of TANF budget allocated toward cash assistance (1997 to 2014)

\begin{tabular}{lc}
\hline Spending category & $\begin{array}{c}\text { Share of reallocation after decline in } \\
\text { cash spending }\end{array}$ \\
\hline Work-Related Investments & $\mathbf{5 6 . 5 \%}$ \\
Childcare assistance & $48.2 \%$ \\
Refundable tax credits & $6.0 \%$ \\
Work activities \& training, transportation & $2.3 \%$ \\
assistance, individual development accounts & $\mathbf{3 9 . 1 \%}$ \\
Other Services & $3.8 \%$ \\
Authorized Under Prior Law & $17.6 \%$ \\
Other Non-Assistance & $17.7 \%$ \\
Transfers to Social Services Block Grant & $\mathbf{1 . 4 \%}$ \\
Family Formation & $1.4 \%$ \\
Pregnancy prevention & $0.0 \%$ \\
Maintenance of two-parent families &
\end{tabular}

Note: Findings derived from models regressing the change in a state's allocation toward the respective category on change in the share of a state's TANF budget allocated toward cash assistance. Only years in which states' allocated a smaller share of TANF budgets toward cash assistance than the year prior are included ( $\mathrm{n}=557$ ). Data spans the 50 states, plus Washington, DC, from 1997 to 2014. The total sum does not equal 100 percent, as some minor categories (such as spending on 'Administrations \& Systems' are not included). Spending data from 2015 to 2016 excluded due to inconsistency in reporting categories with prior years.

Assistance Program (SNAP) have kept the share of household income composed of transfer benefits relative stable over time, despite the decline in TANF. Adding the counterfactual increase in TANF allocations thus has a greater potential poverty-reduction effect in 2016 relative to the years before SNAP/EITC expansions. 
Table 2 presents evidence of how states tend to reallocate their TANF funds after cutting back on spending on cash assistance. From 1997 to 2014, nearly half of the funds pulled back from cash support were reinvested in childcare assistance. ${ }^{8}$ Thus, some lowincome families who now lack cash support from TANF may be more likely than before to benefit from TANF-funded childcare assistance. If so, reverting TANF resources solely to cash assistance may be counterproductive for such families. By contrast, an estimated 40 percent of TANF funds pulled back from cash assistance have been reallocated toward an opaque range of "other services" and family-formation purposes. These "other services" range from funding for overnight camps, textbook subsidies for college students, scholarships for college students from well-off families, the imputed value of Girl Scouts' volunteer time, Alternative to Abortion programs, compulsive gambler assistance, funding for foster care, funding for family-related judicial administration, the creation of a university volleyball court, speaking fees for professional athletes, grants to non-profit organizations, domestic violence services, and much more (Haskins and Weidinger, 2019; Parolin, 2019b; Wolfe, 2020). Put simply, it is unlikely that spending on these alternative programs and services has the same effect on the well-being of low-income families as does direct cash support (National Academy of Sciences, 2019; Duncan and Magnuson, 2013; Shaefer et al., 2019).

That said, a full shift in TANF resources toward cash assistance is not likely to be politically feasible and would require some states to redirect resources away from childcare assistance and other services. Nonetheless, the evidence suggests that a large share of the decline of TANF cash assistance has been redirected toward programs or services that are less likely to reduce poverty. State governments could redirect this non-core TANF spending back to cash assistance to potentially make meaningful reductions in child poverty.

\footnotetext{
${ }^{8}$ TANF reporting categories were changed after 2014, making it difficult to compare how changes in spending prior to 2014 compare to those after 2014. This explains the timeframe of the analysis.
} 


\section{CONCLUSION}

Spending on means-tested cash assistance through the AFDC/TANF program in the U.S. has declined by 78 percent in real terms from 1993 to 2016 . While some studies attribute the declines in cash assistance to rising employment rates among single mothers and the decline of single motherhood more generally, others have attributed the decline in cash assistance to declining real benefit levels and the barriers that low-income families face in attempting to access cash support. This study empirically decomposes changes in cash assistance allocations into each of these components, measuring how variation in incomebased need, participation, and benefit levels contributed to the observed $\$ 25$ billion decline in AFDC/TANF cash assistance allocations from 1993 to 2016.

The primary findings suggest that only around one-fifth of the decline in cash assistance from AFDC/TANF can be attributed to improvements in the economic wellbeing of low-income families. Specifically, this study finds that the rising employment rates among single parents, shifts in the incidence of single parenthood, and changes in other compositional factors can explain only 22 percent (around $\$ 5.5$ billion) of the decline in AFDC/TANF cash assistance allocations. Compositional changes fail to explain 78 percent (\$19.2 billion) of the aggregate decline, indicating that most of the decline in cash assistance is not due to improving living standards or rising employment rates.

Instead, declines in the receipt of TANF cash assistance among households meeting the income-based eligibility standards (participation) contributed to more than 50 percent of the overall decline in cash assistance. Nearly all of the decline in participation rates remains unexplained by compositional differences in the income-eligible households. Instead, federal and state policy decisions designed to inhibit access to cash assistance have led to a sharp decline in participation among families who otherwise meet the income-based eligibility cutoffs (see Appendix III). Had the participation rate of AFDC/TANF benefits remained 
constant from 1993 onward, TANF allocations in 2016 would have amounted to \$15 billion more than the observed value. Declines in TANF cash assistance benefit levels explain about 27 percent of the overall decline in AFDC/TANF allocations. This decline is instead largely due to the non-indexation of TANF benefit values in most states (see Appendix IV). Had benefit levels remained constant, cash assistance spending from TANF would have increased by about $\$ 7.6$ billion in 2016 .

That declining participation and benefit levels contribute more to TANF's decline than changes in the living standards of low-income families should prompt concern as to whether TANF has worked as policymakers intended, and whether the program has inhibited potential reductions in child poverty. As discussed in the Introduction, a vast body of research demonstrates that greater investment into cash assistance for families contributes to lower child poverty rates. This study shows, however, that most of the decline of means-tested cash assistance through AFDC/TANF - around $\$ 19.2$ billion worth - is not due to reduced demand for cash assistance. Were this $\$ 19.2$ billion to be reinvested into cash assistance in 2016 , meaningful progress could be made in reducing levels of poverty among single-mother households. Specifically, the $\$ 19.2$ billion is more than enough to bring all single-mother households above the SPM poverty line. Such an increase in cash support would not require a new redistributive program, as all of the funds are already built into the TANF program, though it would require reallocating TANF funds from other family-related investments back to cash assistance.

These findings also cast skepticism on claims that the declining real value of states' TANF block grants are to blame for declines in cash assistance spending. The counterfactual $\$ 19.2$ billion increase in cash support, combined with current levels of spending on TANF cash assistance, is still less than the $\$ 31$ billion that states spent on all activities within the TANF program in 2016. This is in part due to increases in state MoE spending compensating 
for the declining real value of the TANF block grant. Moreover, a look at states' TANF spending priorities supports the claim that declining block grant values are the cause of declines in spending on TANF cash support. Consider that more than 10 states spent less than 10 percent of their TANF budgets on cash assistance in 2016. For the size of block grants to be a primary constraint on cash assistance, states would presumably need to be using a relatively high share of their current TANF budgets on cash support. That is not the case.

In closing, several limitations of this study should be acknowledged. First, this study's framework for decomposing changes in cash assistance into changes in need, participation, and benefit generosity, and the number of households partially assumes independence among the four components. In other words, the framework assumes that differences in the share of households meeting the income-based eligibility cutoff for TANF will not affect differences in the share of such households that actually collect TANF benefits, and that neither will affect the number of households in the population. If the assumption of independence were not to hold, the utility of the framework would be weakened. More generally, the models and counterfactuals presented in this study are static and do not account for behavioral responses if, say, participation were to be largely expanded. Results should be interpreted accordingly. Moreover, low-income families that do not receive cash assistance support from TANF still may receive TANF-funded support for childcare, transportation costs, or a range of services from compulsive gambler assistance to Healthy Fatherhood initiatives. It is not possible to measure or quantify access to such services in this analysis. Nonetheless, this study maintains that access to other TANF-funded services are important, but are generally no substitute for direct cash assistance when it comes to immediately increasing the economic wellbeing of jobless low-income families (McLaughlin and Rank, 2018; Duncan and Magnuson, 2013; National Academy of Sciences, 2019). 
Moving forward, scholars can apply this study's decomposition framework to understand changes in other social programs, such as benefits from the SNAP or EITC programs. As this study demonstrates, understanding the relative contributions of policy changes compared to compositional differences in shaping trends in social assistance is pertinent for understanding the evolution of the American safety net and its consequences for low-income households. 


\section{REFERENCES}

Bradbury B and Jäntti M. (1999) Child poverty across industrialized nations, Florence: UNICEF.

Brady D, Finnigan R and Hübgen S. (2017) Rethinking the Risks of Poverty: A Framework for Analyzing Prevlances and Penalties. American Journal of Sociology 123 740-786.

Brown HE. (2013) Race, Legality, and the Social Policy Consequences of Anti-Immigration Mobilization. American Sociological Review 78: 290-314.

Congressional Research Service. (2017) Temporary Assistance for Needy Families (TANF): Size of the Population Eligible for and Receiving Cash Assistance. Congressional Research Service Report R44724.

Currie J. (2004) The Take Up of Social Benefits. National Bureau of Economic Research Working Paper Series No. 10488.

Danielson C and Klerman JA. (2008) Did Welfare Reform Cause the Caseload Decline? Social Service Review 82: 703-730.

DiNardo J, Fortin NM and Lemieux T. (1996) Labor Market Institutions and the Distribution of Wages, 1973-1992: A Semiparametric Approach. Econometrica 64: 1001-1044.

Duncan GJ and Magnuson K. (2013) The Long Reach of Early Childhood Poverty. In: Yeung W-JJ and Yap MT (eds) Economic Stress, Human Capital, and Families in Asia: Research and Policy Challenges. Dordrecht: Springer Netherlands, 57-70.

Edin K and Shaefer HL. (2016) \$2.00 A Day: Living on Almost Nothing in America, Boston: Mariner Books.

Falk G. (2014) Temporary Assistance for Needy Families (TANF): Eligibility and Benefit Amounts in State TANF Cash Assistance Programs Congressional Research Service.

Falk G. (2015) Need-Tested Benefits: Estimated Eligibility and Benefit Receipt by Families and Individuals. Congressional Research Service 7-5700.

Falk G. (2016a) The Temporary Assistance for Needy Families (TANF) Block Grant: Responses to Frequently Asked Questions. Congressional Research Service.

Falk G. (2016b) Temporary Assistance for Needy Families (TANF): Size and Characteristics of the Cash Assistance Caseload. Congressional Research Service.

Farrell M, Rich S, Turner L, et al. (2008) Welfare time limits: an updated on state policies, implementation, and effects on families. MDRC.

Floyd I, Burnside A and Schott L. (2018) Policy Brief: TANF Reaching Few Poor Families. Available at: https://www.cbpp.org/research/family-income-support/policy-brief-tanfreaching-few-poor-families/.

Floyd I, Pavetti L and Schott L. (2017) TANF Reaching Few Poor Families. Center on Budget \& Policy Priorities.

Germanis P. (2015) TANF is Broken! It's Time to Reform “Welfare Reform”.

Grogger J, Haider SJ and Klerman J. (2003) Why Did the Welfare Rolls Fall During the 1990's? The Importance of Entry. American Economic Review 93: 288-292.

Grogger J and Karoly LA. (2005) Welfare reform: Effects of a decade of change, Cambridge, Mass. ; London: Harvard University Press. 
Haider SJ, Klerman JA and Roth E. (2003) The Relationship between the Economy and the Welfare Caseload: A Dynamic Approach. Worker Well-Being and Public Policy 22: 39-69.

Haskins R. (2016) TANF at Age 20: Work Still Works. Journal of Policy Analysis and Management 35: 224-231.

Haskins R and Weidinger M. (2019) The Temporary Assistance for Needy Families Program: Time for Improvements. The ANNALS of the American Academy of Political and Social Science 686: 286-309.

Herd P and Moynihan DP. (2018) Administrative burden : policymaking by other means, New York: Russell Sage Foundation.

Hoynes H and MaCurdy T. (1994) Has the Decline in Benefits Shortened Welfare Spells? The American Economic Review 84: 43-48.

McCabe J. (2019) Rich State, Poor State: The Case for Reforming Federal Grants. Niskanen Center Policy Essay.

McLaughlin M and Rank MR. (2018) Estimating the Economic Cost of Childhood Poverty in the United States. Social Work Research 42: 73-83.

Meyer BD, Wallace KCM and Sullivan JX. (2009) The Under-Reporting of Transfers in Household Surveys: Its Nature and Consequences. National Bureau of Economic Research Working Paper Series No. 15181.

National Academy of Sciences. (2019) A Roadmap to Reducing Child Poverty, Washington, DC: The National Academies Press.

Parolin Z. (2019a) The Effect of Benefit Underreporting on Estimates of Poverty in the United States. Social Indicators Research.

Parolin Z. (2019b) Temporary Assistance for Needy Families and the Black-White Child Poverty Gap. Socio-Economic Review Online First.

Parolin Z and Brady D. (2019) Extreme child poverty and the role of social policy in the united states. Journal of Poverty and Social Justice 27: 3-22.

Parolin Z and Luigjes C. (2019) Incentive to Retrench? Investigating the Interactions of State and Federal Social Assistance Programs after Welfare Reform. Social Service Review 93: 305-339.

Prabhu M. (2019) Welfare rolls in Georgia cut by nearly two-thirds since 2006. The Atlantic Journal-Constituion Atlanta, GA.

Quadagno J. (1998) Race, Class, and Gender in the U.S. Welfare State Nixon's Failed Family Assistance Plan. Power Resource Theory and the Welfare State. University of Toronto Press, 250-282.

Quadagno JS. (1994) The color of welfare : how racism undermined the war on poverty, New York ; Oxford: Oxford University Press.

Rainwater L and Smeeding TM. (2003) Poor Kids in a Rich Country: America's Children in Comparative Perspective: Russell Sage Foundation.

Schoeni RF and Blank RM. (2000) What has Welfare Reform Accomplished? Impacts on Welfare Participation, Employment, Income, Poverty, and Family Structure. National Bureau of Economic Research Working Paper Series No. 7627. 
Schott L, Pavetti L and Floyd I. (2018) How States Use Federal and State Funds Under the TANF Block Grant. Center on Budget \& Policy Priorities.

Schram S, Soss J and Fording RC. (2003) Race and the Politics of Welfare Reform, Ann Arbor: University of Michigan Press.

Shaefer HL, Edin K, Fusaro V, et al. (2019) The Decline of Cash Assistance and the WellBeing of Poor Households with Children. Social Forces.

Social Security Administration. (2005) Annual Statistical Supplement. Available at: https://www.ssa.gov/policy/docs/statcomps/supplement/2005/9g.html.

Soss J, Fording RC and Schram S. (2011) Disciplining the poor : neoliberal paternalism and the persistent power of race, Chicago: University of Chicago Press.

Soss J, Fording RC and Schram SF. (2008) The Color of Devolution: Race, Federalism, and the Politics of Social Control. American Journal of Political Science 52: 536-553.

Soss J, Schram SF, Vartanian TP, et al. (2001) Setting the terms of relief: Explaining state policy choices in the devolution revolution. American Journal of Political Science 45: 378-395.

Stanley M, Floyd I and Hill M. (2016) TANF cash benefits have fallen by more than 20 percent in most states and continue to erode. Center for Budget \& Policy Priorities.

Stevens K, Fox L and Heggeness M. (2018) Precision in Measurement: Using State-Level SNAP Administrative Records and the Transfer Income Model (TRIM3) to Evaluate Poverty Measurement. U.S. Census Bureau Working Paper Number: SEHSDWP2018-15.

Stuber J and Kronebusch K. (2004) Stigma and other determinants of participation in TANF and Medicaid. Journal of Policy Analysis and Management 23: 509-530.

Wheaton L and Tran V. (2018) The Antipoverty Effects of the Supplemental Nutrition Assistance Program. The Urban Institute Research Report.

Winship S. (2016) Poverty After Welfare Reform. Manhattan Institute.

Wolfe A. (2020) The governor, the quarterback and the concussion discussion. Mississippi Today. Mississippi.

Ziliak JP. (2015) Temporary Assistance for Needy Families. NBER working paper(Online) working paper 21038. Cambridge, Mass.: National Bureau of Economic Research,, 1 online resource. 
Appendix I: Trends in cash assistance spending in administrative records compared to TRIM3-adjusted CPS ASEC and unadjusted CPS ASEC, 1998 to 2016

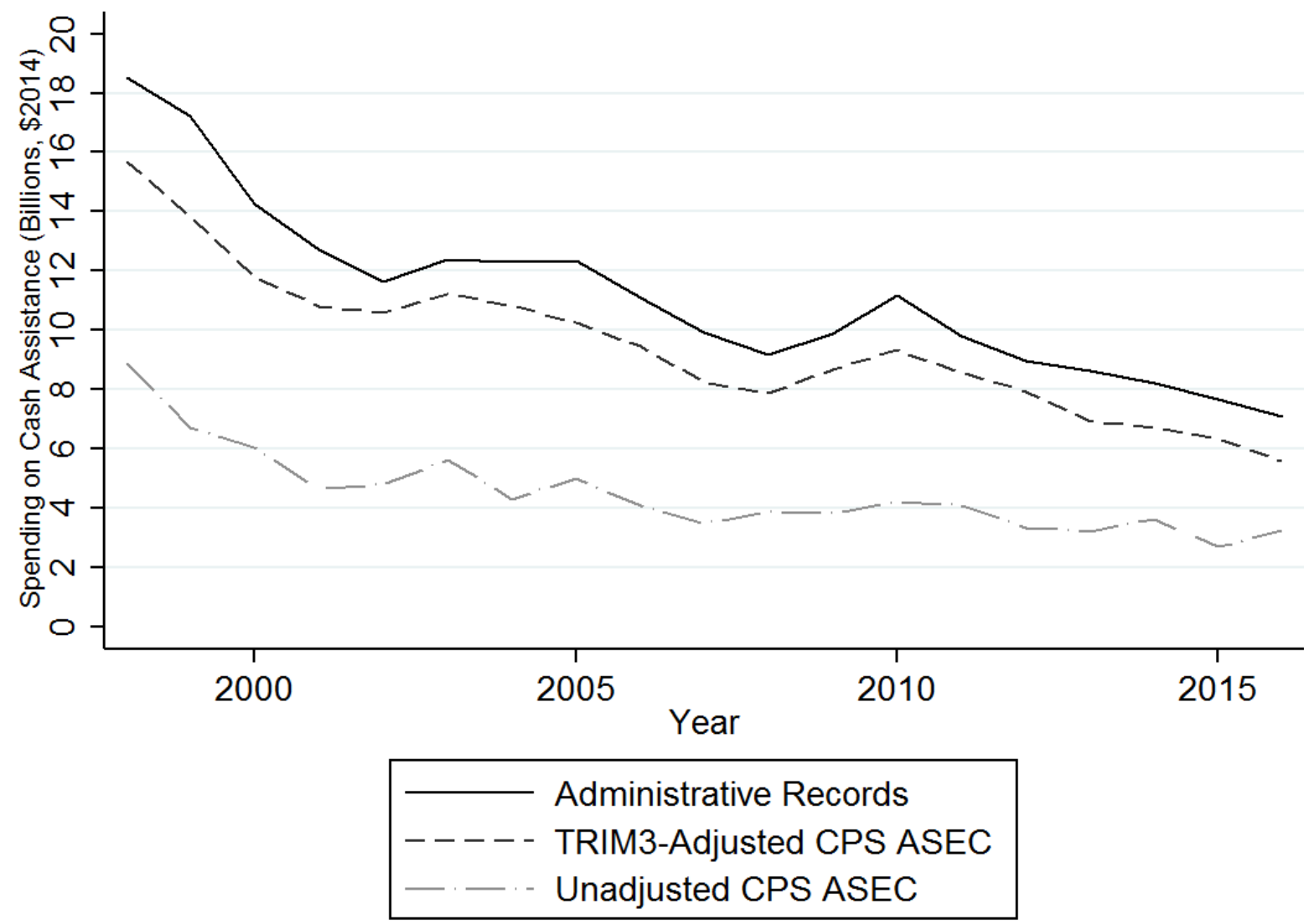

Note: Administrative records on TANF cash assistance allocations from Center on Budget for Policy Priorities and U.S. Department of Health \& Human Services.

Reading Note: The TRIM3-adjusted CPS ASEC more accurately tracks administrative records with respect to levels and trends in TANF benefit allocations compared to the unadjusted CPS ASEC. 
Appendix II: Associations of administrative records on TANF caseloads with TRIM3 estimates of caseloads (black line) and unadjusted CPS estimates of caseloads (gray line)
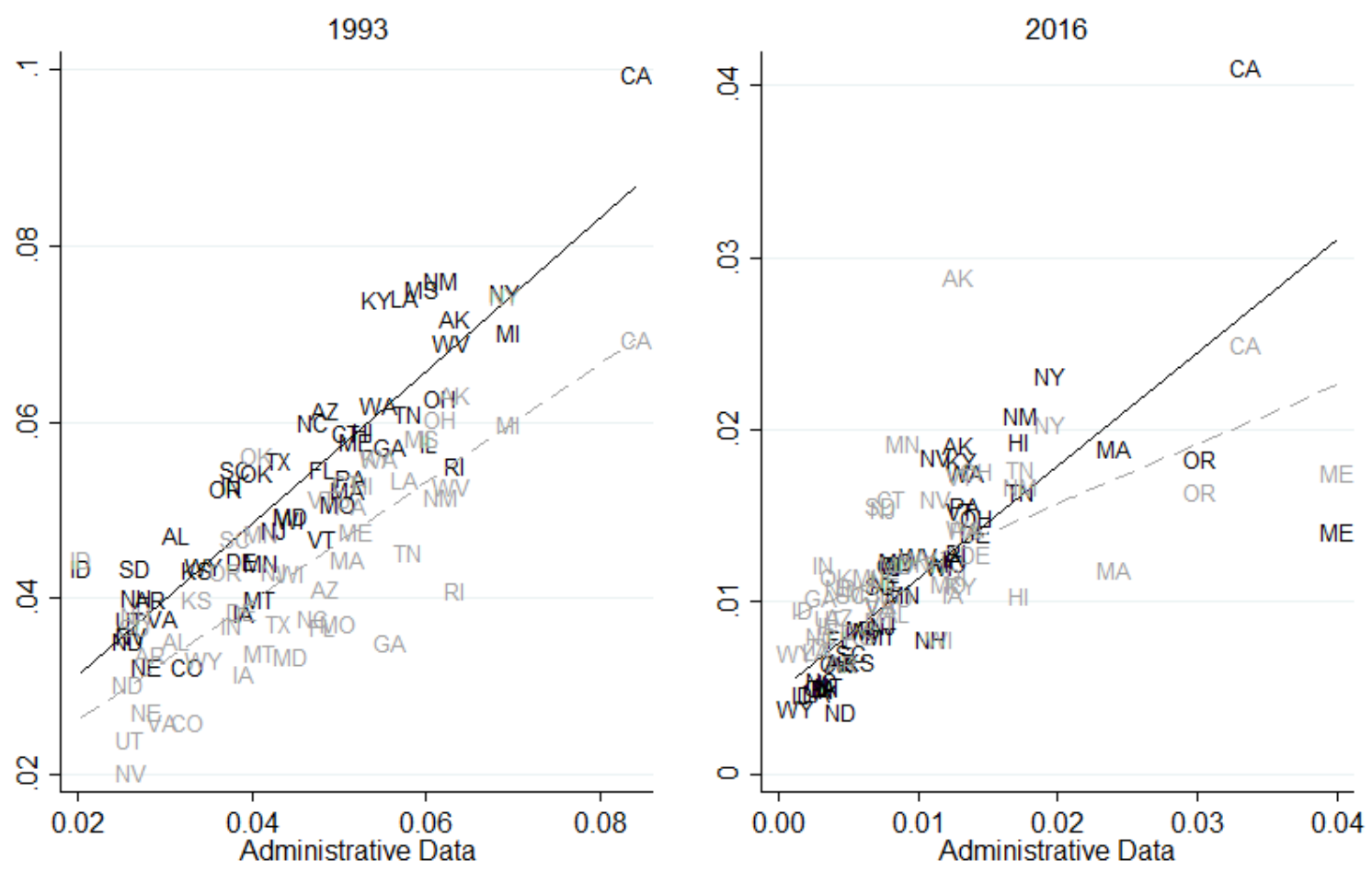

TRIM3-Adjusted CPS

----- Unadjusted CPS

Note: Y-Axis: TANF caseload to population ratio according to TANF administrative records.

Reading Note: In both 1993 and 2016, the state-level correlation between administrative records of TANF caseload shares and TRIM3 estimates of caseload shares is stronger ( $r=0.89$ in 1993, 0.80 in 2016) than the correlation between administrative records and estimates from the unadjusted CPS $(\mathrm{r}=0.79$ in 1993, 0.60 in 2016). This provides further evidence that the use of TRIM3 is an improvement over the use of the unadjusted CPS ASEC. Nonetheless, Appendix V replicates the results using the unadjusted CPS ASEC and finds findings comparable to the primary analysis. 
Appendix III: Linear Probability Models Estimating Effect of State TANF Policies on Participation in TANF among Eligible Households (1998 to 2016)

\begin{tabular}{lcc}
\hline DV: TANF Participation & $\begin{array}{c}\text { M1: Single TANF Policy } \\
\text { in Model }\end{array}$ & $\begin{array}{c}\text { M2: All TANF Policies in } \\
\text { Model }\end{array}$ \\
\hline Length of Lifetime Time Limit & $.004^{* * *}$ & $.004^{* * *}$ \\
& $(.001)$ & $(.001)$ \\
Presence of Immediate Sanctions & $-.076^{* *}$ & -.035 \\
& $(.029)$ & $(.028)$ \\
Presence of TANF Diversion Policies & -.022 & -.025 \\
& $(.015)$ & $(.015)$ \\
Strictest Sanction: TANF Unit's Case is & $-.096^{* * *}$ & $-.081^{* *}$ \\
Closed & $(.023)$ & $(.024)$ \\
& & \\
Household Controls & $\mathrm{X}$ & $\mathrm{X}$ \\
State Fixed Effects & $\mathrm{X}$ & $\mathrm{X}$ \\
Year Fixed Effects & $\mathrm{X}$ & $\mathrm{X}$ \\
\hline Number of Households in Sample & 89,750 & 89,750 \\
\hline
\end{tabular}

Note: ${ }^{*} p<0.05,{ }^{* *} p<0.01,{ }^{* * *} p<0.001$. Sample limited to households eligible for TANF. Standard errors in parentheses. Lifetime time limits range from 12 to 60. All other indicators of state TANF policies are binary variables. TANF indicators downloaded from Urban Institute's Welfare Rules Database.

Reading Note: Results from Model 1 suggest that longer lifetime limits contribute to higher TANF participation among households meeting the income-based eligibility standards. However, the presence of immediate sanctions for TANF violations in a state, or the closing of a family's TANF case as the state's strictest sanctioning policy, is associated with lower TANF participation. The presence of TANF diversion policies is negatively signed, but statistically insignificant. In Model 2, when all the indicators are added into the same estimation, only the length of the lifetime time limit and closing the family's TANF case as the strictest sanctioning policy remain statistically significant. The results corroborate the claims in the paper that states' TANF policy rules contribute to variation in the participation of TANF benefits. 
Appendix IV: OLS Estimate of Effect of State's Maximum AFDC/TANF Benefit Value on Observed Levels of Benefit Receipt among Households Receiving TANF (1993 to 2016)

\begin{tabular}{lc}
\hline DV: Log of Annual AFDC/TANF Benefits Received & M1 \\
\hline Log of State's Maximum AFDC/TANF Benefit Value & $.802^{* *}$ \\
for Family of Three & $(.235)$ \\
& \\
& $\mathrm{X}$ \\
Household Controls & $\mathrm{X}$ \\
State Fixed Effects & $\mathrm{X}$ \\
Year Fixed Effects & 50,781
\end{tabular}

Number of Households in Sample 50,781

Note: ${ }^{*} p<0.05,{ }^{* *} p<0.01,{ }^{* * *} p<0.001$. Sample limited to households receiving AFDC/TANF. Standard errors in parentheses. State AFDC/TANF values from University of Kentucky Center for Poverty Research National Welfare Database.

Reading Note: The results show a strong relationship between a state's maximum AFDC/TANF benefit values and the level of AFDC/TANF benefits that a participating household receives. The results corroborate the claims in the paper that states' TANF policy decisions contribute to variation in TANF benefit generosity. 
Appendix V: Replication of decomposition using unadjusted CPS ASEC without TRIM3 modifications for benefit underreporting

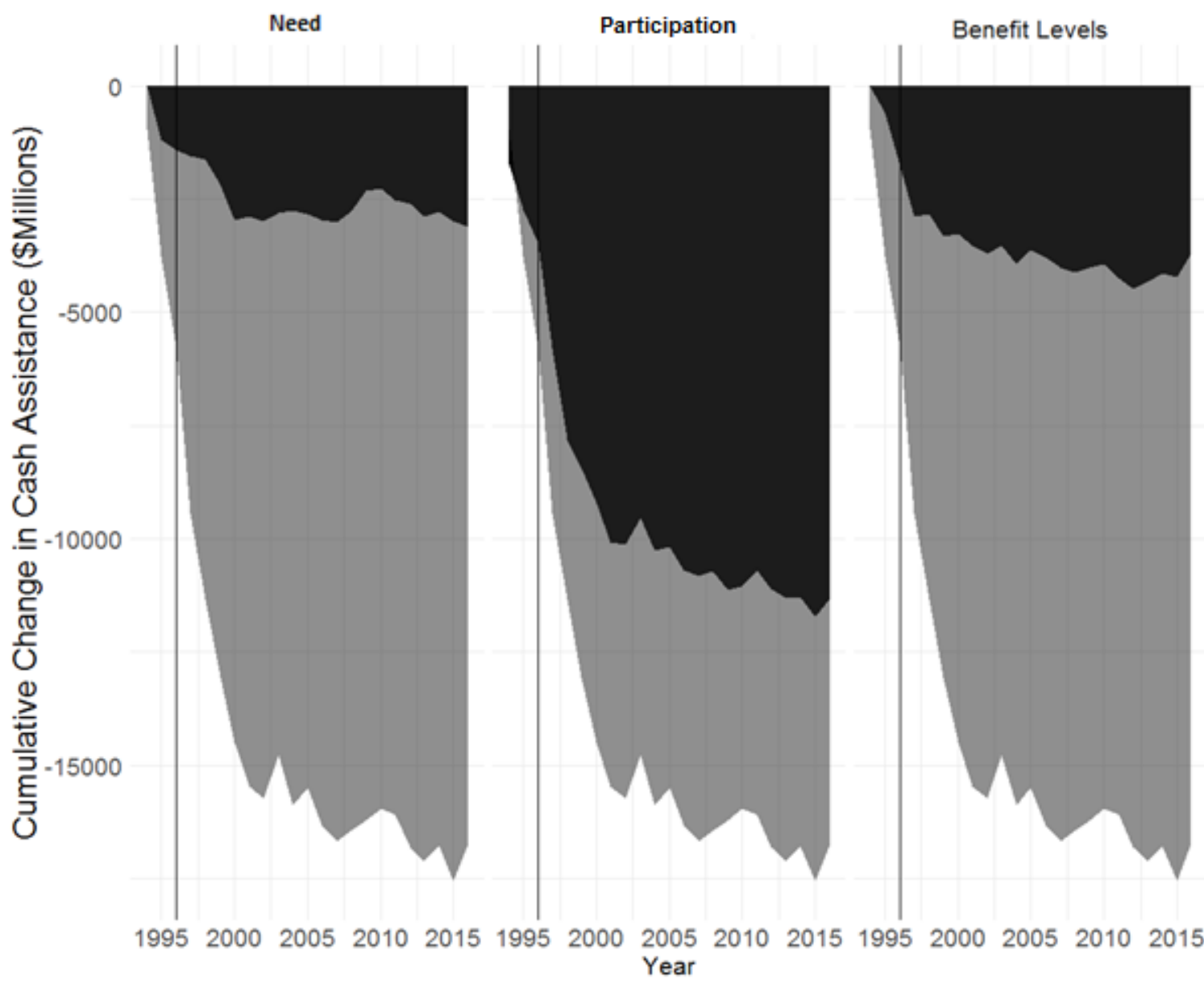

Cumulative Change Due to Given Component Cumulative Change

Note: Vertical line represents transition from AFDC to TANF.

Reading Note: Even when using the unadjusted CPS ASEC, which excludes the TRIM3 adjustments for TANF benefit underreporting, the primary findings hold. Now, declines in participation make up 61 percent of the decline of cash assistance, rather than 52 percent in the primary findings. Declines in need compose 17 percent of the decline, rather than 21 percent in the primary findings. Declines in benefit generosity compose 18 percent of the decline, rather than 28 percent in the primary findings. In sum, the sensitivity check strengthens the study's primary findings that most of the decline in cash assistance from TANF can be attributed to declines in participation. 
Appendix VI: Results with alternative conceptualization of need that removes households potentially exceeding lifetime time limits for TANF benefit receipt from need classification

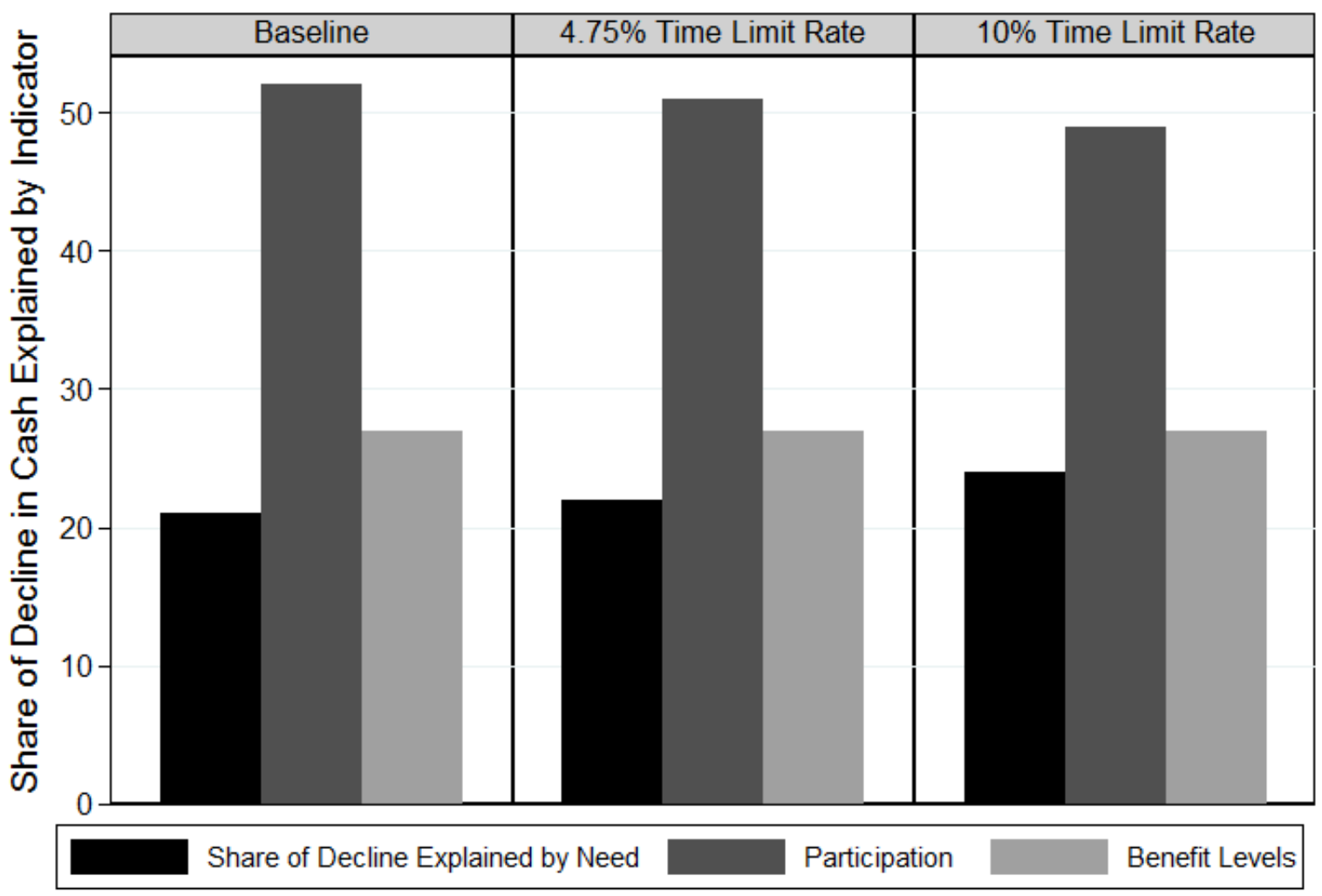

Note: Bars represent percent of decline of TANF cash assistance explained given component under the specified scenario.

Reading Note: One could argue that if a household receives TANF benefits for longer than the state's lifetime time limit, then the household should not quality as being "eligible" for TANF cash assistance. This study's concept of "need" is not restricted to households who are strictly eligible for TANF (as discussed, the study instead conceptualizes need as meeting the income-based eligibility requirements). Nonetheless, the figure above visualizes two counterfactual scenarios in which a given set of households in need are removed from need due to potentially violating lifetime time limits. In 2008 , Farrell et. al. found that between $2-3 \%$ of all TANF exists were due to time limits. Let's assume that climbs at a rate of 0.25 p.p. per year and thus reaches $4.75 \%$ in 2016 (middle panel). In a more extreme simulation, let's assume that time limit exits are closer to $10 \%$ in 2016 (right panel). I randomly moving households out of need in 2016 by the given percent and re-run the analysis to understand the extent to which need and participation among households in need change in importance in explaining the decline of TANF cash assistance. However, recalculating the contribution of need, participation, and benefit levels shows little difference with the primary ("baseline") findings. 